\title{
GERAK DAN RASA DALAM TARI MERAK JAWA BARAT
}

\author{
Venny Agustin Hidayat \\ Pengkajian Tari, Seni Pertunjukan, \\ Pascasarjana Institut Seni Indonesia Yogyakarta \\ e-mail: vennyagustintah@gmail.com
}

Diterima : 8 Agustus 202ㅁ․ Disetujui : $2 \underline{5}$ November 2020. Dipublikasikan : 1 Desember 2020

terbuka di bawah lisensi CC BY 4.0 (https://creativecommons.org/licenses/by/4.0/)

\begin{abstract}
ABSTRAK
Gerak merupakan unsur utama dari tari. Gerak di dalam tari bukanlah gerak yang realistis, melainkan gerak yang telah diberi bentuk ekspresif dan estetis. Gerak tari selalu melibatkan unsur anggota badan manusia dan berfungsi sebagai media untuk mengkomunikasikan maksud dari pembentukan gerak. Jenis gerak tari yang digunakan, yaitu gerak maknawi, gerak murni, dan gesture. Selain gerak tari, terdapat elemen-elemen ruang, waktu, dan tenaga dalam menari.Metode penelitian yang digunakan, yaitu pendekatan kualitatif. Tujuannya agar penelitian dapat ditemukan, dikembangkan, dibuktikan, dan dapat digambarkan secara sistematis tentang gerak pada tari Merak, sehingga menimbulkan rasa untuk melakukannya. Subjek penelitiannya adalah para anggota yang berada di sanggar tari, terdiri dari para penari merak, pelopor, dan pengola sanggar Pusbitari Bandung. Suatu tarian apabila disajikan sebagai objek seni menjadi sebuah pengalaman bagi para pengamat untuk di hayati dan dimengerti, melalui struktur sensasi, persepsi, dan perasaan dalam menggerakkannya. Sering kali dikatakan bahwa muridmurid pemula tidak siap untuk mencipta dan mendapatkan ketubuhan baru. Melalui kesempatan yang diulangulang bagi aktivitas kreatif yang diarahkan sendiri, seorang penari dapat mengembangkan potensi kreatifnya. Pengalaman kreatif yang pertama dalam tari, dialami dengan beberapa tingkat kecemasan. Tingkat kecemasan ini dapat kita pahami dan pengalaman seperti itu sebaiknya diarahkan agar para murid-murid dapat mengatasi rasa takutnya.
\end{abstract}

Kata Kunci: gerak, kualitatif, rasa, tari merak.

\begin{abstract}
Motion is the main element of dance. Motion in dance is not a realistic movement, but a movement that has been given an expressive and aesthetic form. Dance moves always involve elements of the human body and function as a medium to communicate the purpose of motion formation. Types of dance movements used, namely meaningful motion, pure motion, and gesture. In addition to dance moves, there are elements of space, time, and energy in dancing. The research method used is a qualitative approach. The goal is that research can be found, developed, proven, and can be described systematically about the movements of the Peacock dance, giving rise to a sense of doing so. The subjects of the research were the members who were in the dance studio, consisting of peacock dancers, pioneers, and processors at the Bandung Pusbitari Studio. A dance when presented as an object of art becomes an experience for observers to be lived and understood, through the structure of sensation, perception, and feeling in moving it. It is often said that novice students are not ready to create and obtain new bodies. Through repeated opportunities for self-directed creative activities, a dancer can develop their creative potential. The first creative experience in dance, experienced with some level of anxiety. This level of anxiety can be understood by us and such experiences should be directed so that students can overcome their fears.
\end{abstract}

Keyword: motion, qualitative, taste, peacock dance.

\section{PENDAHULUAN}

Gerak merupakan unsur utama dari tari. Gerak di dalam tari bukanlah gerak yang realistis, melainkan gerak yang telah diberi bentuk ekspresif dan estetis. Gerak tari selalu melibatkan unsur anggota badan manusia dan berfungsi sebagai media untuk mengkomunikasikan maksud dari pembentukan gerak. Gerak di dalam tari diberi sentuhan seni, misalnya gerak berjalan, lari, bermain, seakan terbang, mencagkul, dan sebagainya. Jika diberi sentuhan emosional yang mengandung nilai seni, maka gerakgerak keseharian tersebut akan tampak lain. 
Masing-masing daerah memiliki budaya dan selera yang berbeda-beda, bisa dilihat dari bentuk gerak dan teknik memperagakannya. Gerakan tari membutuhkan proses pengolahan atau penggarapan terlebih dahulu. Jenis gerak tari yang digunakan, yaitu gerak maknawi dan gerak murni. Gerak yang telah diubah menjadi gerak indah yang bermakna dalam pengolahannya mengandung suatu pengertian atau maksud tertentu. Misalnya, gerak yang melambangkan burung terbang atau mengais tanah.

Gerak murni adalah gerak yang mengutamakan keindahan. Gerak ini tidak menyimbolkan sesuatu, tetapi dibuat agar tarian tampak estetis, misalnya gerak memutar pergelangan tangan dan gerak tangan ke samping sejajar dengan bahu. Selain keindahan gerak maknawi dan gerak murni, terdapat gesture. Bersifat menirukan, imitative, yaitu gerak peniruan dari binatang dan alam.

Gerak imitative terjadi pada tari Merak, Jawa Barat. Gerak di dalam tarian ini menirukan tingkah laku burung merak, seperti gerak yang menggambarkan bermain dengan merak betina dan jantan. Ketika sedang terbang, mengais tanah, menggaruk-garuk tubuhnya, gerak kepala yang terpatah-patah dari kanan ke kiri atau sebaliknya, mencari makan, dan berbagai macam tingah laku burung merak.

Selain gerak tari, terdapat elemen-elemen ruang, waktu, dan tenaga dalam menari. Ruang terbagi menjadi dua jenis, yaitu ruang yang diciptakan penari dan ruang gerak untuk menari. Salah satu unsur elemen dasar dalam tari, terdapat tiga tingkat level, yakni gerak tinggi, sedang, dan rendah. Gerak tinggi, contohnya penari memperagakan gerak meloncat dengan gerakan tangan ke atas, gerak terbang, gerak melebarkan sayap dan seakan-akan terbang atau berjalan dengan ujung jari kaki yang berjarak. Sedang, contohnya penari memperagakan gerak mendak dengan merendahkan kaki. Posisi lutut menekuk ke depan $70^{\circ} \mathrm{C}$ dan posisi betis $290^{\circ} \mathrm{C}$. Rendah, contohnya penari memperagakan gerak duduk dan menggerakan motif gegebreg. Terdapat dua peragaan gerak di dalam menari, yaitu tempo dimulai pada waktu penari bergerak hingga selesai, terdapat gerakan cepat, lambat, dan bervariatif. Irama, yakni waktu yang di gunakan untuk menuntaskan gerak yang berkaitan dengan tempo dan dinamika gerak, cepat ke sedang dan sedang ke cepat atau lambat ke cepat sesuai dengan aksara gerak dan tempo gerak yang tidak sama.

Elemen-elemen gerak tersebut akan di jabarkan dan di contohkan pada tari Merak yang berasal dari Jawa Barat. Mulai dari gerak, ruang, dan waktu, beserta tekniknya. Tempat yang digunakan sebagai objek penelitian, yaitu salah satu sanggar seni di Yogyakarta, terdapat kelas tari Sunda (tari Merak). Peneliti akhirnya mengamati tari Merak yang berada di Sanggar LPK Natya Lakshita, Yogyakarta. Dengan melibatkan para penari sanggar seni yang mengikuti kelas tari Sunda (tari Merak).

Tarian Sunda yang digerakkan dengan ketubuhan Jawa, apakah sama cara dan hasil menggerakkannya ataukah berbeda. Dikarenakan tari Merak dan penari Sunda adalah sesuatu yang baru, akan tetapi para penari belum tentu baku. Sehingga hal itulah yang akan di amati dalam pencarian gerak tari Merak. Bagaimana cara agar merubah perilaku Jawa menjadi perilaku Sunda, yang di gambarkan dalam gerak tari Merak Jawa Barat?

\section{METODE PENELITIAN}

Metode penelitian yang digunakan, yaitu pendekatan kualitatif. Tujuannya agar penelitian dapat ditemukan, dikembangkan, dibuktikan, dan dapat digambarkan secara sistematis tentang gerak pada tari Merak, sehingga menimbulkan rasa untuk melakukannya. Gerak yang dilakukan akan menimbulkan efek gerak baru dan pengetahuan baru, dilakukan dengan tubuh yang baru. Tubuh yang baru dalam artian tidak pada porsi yang aslinya, karena yang menggerakkan adalah tubuh orang Jawa.

Penelitian ini lebih dominan menggunakan metode wawancara yang sudah di buat, terkadang berubah dalam urutan pertanyaannya (wawancara semi terstruktur). Tanpa sengaja peneliti menggunakan wawancara kelompok, dengan tiga orang penari, dan dilaksanakan pada waktu yang bersamaan. Peneliti memiliki keterbatasan untuk menjangkau seluruhnya, maka peneliti menggunakan teknik diskusi kelompok secara terarah.

Objek penelitiannya, tari Merak yang berada di sanggar seni. Subjek penelitiannya adalah para anggota yang berada di sanggar tari, yang terdiri dari para penari merak, pelopor, dan pengola sanggar Pusbitari Bandung. Durasi wawancara rata-rata, yaitu 18 menit. Lokasi pengamatan, yaitu Perumahan Jatimulyo Baru, Blok G, No.13-14, Kricak, Tegalrejo, Kota Yogyakarta, Daerah Istimewa Yogyakarta, 55242. Waktu pengamatannya dilaksanakan kurang lebih empat bulan lebih terhitung dari tanggal 25 Februari sampai 06 Juni 2019. Penelitiannya di hari dan lokasi yang berbeda-beda, dengan anggota sanggar tari.

\section{HASIL DAN PEMBAHASAN}

\section{Sanggar LPK Natya Lakshita}

Dari tangan Didik Nini Thowok hadirlah Sanggar Tari Natya Lakshita. Eksistensi sanggar seni sudah sangat lama, bahkan layak disebut legend. Didik Hadiprayitno, nama asli Didik Nini Thowok, mendirikan sanggar seni sejak 02 Februari 1980. Di sinilah Didik membagi ilmunya tentang tari pada generasi muda, sekaligus menjadi pelestari kekayaan budaya tradisional yang sudah mulai ditinggalkan anak muda zaman sekarang. Seiring perkembangan waktu, Sanggar seni berubah menjadi Lembaga Pendidikan dan Kepelatihan (LPK), sanggar ini memperluas pelatihan hingga soal tata rias dan manajemen pertunjukan. Tahun 1994, terdaftar sebagai anggota Himpunan Penyelenggara Kursus Indonesia. 
Meski berbasis di kota budaya Jawa dan Didik Nini Thowok sendiri juga punya background sebagai orang Jawa, namun sanggar ini tidak hanya mengajarkan tari-tarian Jawa saja. Hal ini menunjukkan kemampuan Didik Nini Thowok dalam mendalami seni tari lintas budaya. Di Sanggar diajarkan tari dari berbagai daerah lain di tanah air seperti tari tradisional daerah Sunda (tari Merak dan Jaipong), tari Cirebon, tari Tiongkok, tari Bali, tari Nusantara. Termasuk juga tarian dangdut, hingga tari Kontemporer. Hingga kini belasan ribu siswa telah lulus dari sanggar yang dikelola Didik Nini Thowok. Tidak sedikit yang menjadi penari profesional yang kemudian mendirikan sanggar tari serupa.

\section{A. Genre Tari (aliran)}

Dalam hal ini mencakup aliran gerakan tari dan dapat dikelompokan menjadi tiga kategori.

\section{- Tari tradisional}

Seni tari tradisional: tarian yang diwariskan dari masa ke masa sejak zaman dahulu, yang dilestarikan lalu menjadi budaya di suatu daerah. Dalam tarian tersebut terdapat nilai, filosofi, simbol, dan unsur religi. Tari tradisional biasanya tidak berubah dari masa ke masa, dari segi pakaian tari, rias, dan musik pengiring. Tujuannya agar tetap terjaga dan tidak hilang dimakan zaman.

Tari tradisional klasik: Merupakan tarian tradisional yang dikembangkan oleh kalangan bangsawan istana atau keraton. Jika tarian tersebut diganti atau hanya sekedar ditambah, maka sah-sah saja. Cirinya adalah tarian yang bernuansa anggun dan berwibawa, juga gerak dan aksesoris mewah yang dikenakan oleh penari. Biasanya tarian ini diadakan untuk menyambut sebuah tamu kehormatan dan berkebangsaan. Contoh dari tarian ini adalah Tari Bedhaya Srimpi asal Jawa Tengah, Tari Sang Hyang asal Bali, dan tari Merak karya Tjeje Soemantri pada tahun 1950.

Tari tradisional kerakyatan: Dikembangkan dari masyarakat kaum bawah atau rakyat biasa. Berbeda dengan tradisional klasik, tarian yang satu ini gerakannya tidak terlalu baku. Bahkan bisa di satu padukan dengan gerakan baru yang lebih menarik. Karena tarian ini tidak harus memilki syarat yang berbelit untuk melakukannya. Dari segi gerakan maupun penampilan. Contoh dari tarian ini adalah Tari Jaipong asal Jawa Barat.

- Tari kreasi baru

Sebuah tarian yang dikembangkan oleh seorang penata tari. Gerakan yang ditampilkan bersifat bebas, tetapi masih tetap dalam kaidah gerakan tari yang estetis dan indah. Riasan dan iringan musik dalam tari kreasi baru juga sangat beragam. Tergantung dengan tema dan tujuan yang ingin dibawakan oleh penari tersebut.

\section{- Tari kontemporer}

Merupakan sebuah tarian yang mengunakan gerakan-gerakan yang bersifat simbolik, unik, dan mengandung pesan tertentu didalamnya. Irama musik yang digunakan tidak biasa, mulai dari musik sederhana, orkestra, sampai musik flutyloops yang diambil dari teknologi musik digital. Rias wajah dan kostum terbilang aneh sesuai dengan tema yang dibawakan. Terbilang aneh, karena tarian yang biasanya membawakan sebuah gerakan berbentuk mengenang sebuah perjuangan seorang tokoh atau kejadian atau juga hari tertentu yang mana meninggalkan cerita khusus.

\section{B. Elemen-Elemen Tari}

Gerak yang dilakukan oleh para penari dapat dihasilkan melalui pencarian gerak atau penjelajahan. Pencarian gerak merupakan proses berpikir, berimajinasi, merasakan, dan merespon suatu objek yang diperoleh melalui panca indera. Gerak harus diiringi dengan cara menimbulkan rasa (ekspresi). Hasil untuk mendapatkan rasa dalam menggerakan banyak tekniknya, diantaranya tenaga, gerak yang tuntas, gerak mana yang harus berhenti-mengalun, gerak yang menggunakan tenaga (harus tepat), dan olah tubuh ketika akan memulai belajar menari. Semua itu dapat menimbulkan imajinasi yang merangsang terjadinya respon gerak spontan.

Sedangkan penjelajahan rasa, seperti suka, panas, dingin, marah, senang, dan sedih akan membantu pencarian gerak ekspresif. Untuk mempermudah mencari dan merespon gerak, maka harus mengetahui tema tari. Contohnya: binatang, gerak yang muncul adalah menirukan tingkah laku binatang (burung merak).

Ruang kesundaannya tercipta karena adanya desain (bantuan), instrument musik, kostum tari, dan gaya menari (gerak). Peneliti menemukan pengembangan dari gerak yang dilakukan oleh beberapa penari. Tari yang sama dengan ketubuhan yang berbeda akan menimbulkan rasa menari yang berbeda, sehingga menimbulkan persepsi, sensasi yang dilihat oleh pengamat. Sehingga hasil dari peneliti mengamati gerak yang berada di sisi penari Jawa, menimbulkan sensasi dan persepsi yang berbeda.

Elemen dasar tari yaitu gerak, selain elemen gerak terdapat ruang, waktu, dan tenaga.

1. Ruang

Rangkaian yang sudah tersusun diperlukan ruang gerak, berupa rangkaian gerak dengan volume sempit dan gerak dengan volume luas yang di rubah, disesuaikan dengan kebutuhan. Volume yang sempit dalam tari Merak, bisa di contohkan dengan motif kokoer dan motif gegebreg. Yang sudah di gerakkan oleh Fatma, Fetri, dan Ayak, mereka mencontohkan dengan gerak yang sama dan hitungan yang sama. Volume sempit pada tari Merak, yaitu gerak dengan tangan, badan, dan kaki membutuhkan ruang yang sempit.

\section{a. Motif kokoer}

Geraknya dengan kaki seperti mengais tanah dan menggeleng-geleng kepala selayaknya seperti burung merak. Gerakan yang mengais tanah. 
Ketika hitungan 1 , jari kaki menekan dan hitungan 2 jari kaki menyeret. Hitungan 1 dan 2, di ulang sebanyak 9x, jika di samakan dengan irama musik. Tangan di letakkan di samping badan masing-masing. Jari-jari tangan memegang sayap dari kostum merak. Mengayunkan jari-jari tangan kedepan dan ke belakang.

b. Motif gegebreng

Gegebreng (menggerakan bahu), ketika menari, bahu digerakkan ke depan dan ke belakang, dengan menggunakan tenaga. Dimulai dari hitungan 1, 2, 3 dan berakhir di hitungan 4. Posisi dari motif ini menggerakannya dengan duduk jongkok. Kedua tangan di letakkan di kaki bagian atas

Volume yang luas di contohkan oleh Memei, Keny, dan Tanti. Mereka mencontohkan dengan motif merak ulin dan merak hibeur. Volume yang luas menghasilkan gerak yang besar dan lembar/besar pula.

c. Merak ulin

Gerakan yang lebih dominan bermain ketika menari. Salah satu motif dengan tarian yang berpasangan, dikarenakan terdapat gerak penari 1 dan penari 2. Merak ini lebih bermain gerak yang luas dan terdapat permainan tempo didalamnya. Tempo cepat-lambat dan bervariatif sehingga menjadikan irama gerak (menuntaskan gerak dan dinamika gerak, cepat ke sedang dan sedang ke cepat atau lambat ke cepat sesuai dengan aksara gerak dan tempo gerak yang tidak sama)

d. Merak hibeur

Merak terbang. Hitung dalam tarian sampai 1x8+4 lalu ganti motif gerak. Hitungan 1, 2, membuka sayap dan mengangkat kedua tumit, hitungan 3, secara perlahan berjalan dengan satu hitungan dua kali langkah. Sayap yang berada di tangan, seolah-olah terbang, yang awalnya sejajar dengan baru, lalu berubah ketika pindah hitungan, menjadi tidak seimbang. Jika tangan kanan lurus ke bawah, berarti tangan kiri, lurus ke atas, begitupun sebaliknya. Dimulai dari hitungan 3, 4 $5,6,7,8$, dan pengulangan 1 sampai 4 hitungan.

2. Waktu

Terdapat dua peragaan gerak tari, yaitu tempo dan irama. Gerak yang dicontohkan oleh kebanyakan dari penari, hasilnya sama. Mereka bisa menyesuaikan tempo dan irama pada gerak tari Merak ketika menggabungkan iringan musik.

\section{Tenaga Dalam Menari}

Faktor-faktor yang bekerjasama dengan tenaga, yaitu intensitas gerak, banyak sedikitnya tenaga yang dipakai sehingga terlihat berkesinambungan. Aksen gerak, memperagakan gerak tari sesuai kebutuhan dan tidak merata, misal: cepat, kuat, lembut, dan enteng. Kualitas gerak, penyaluran tenaga sesuai dengan pengaturan nafas, sehingga terkesan bagus/baik. Kualitas gerak yang luwes dilakukan tanpa paksaan, dengan gerak yang sesuai dengan ketentuan, karena gaya tari tidak memandang penari wanita kurus atau gemuk, tinggi atau pendek, cantik atau jelek.

\section{Teknik}

Dalam tari, teknik dipahami sebagai suatu cara untuk mengerjakan seluruh proses, baik metal maupun fisik. Sehingga para penari, mewujudkan pengalaman estetisnya dalam sebuah tarian. Teknik dalam gerak terdapat tiga jenis, yaitu teknik bentuk, medium, dan isntrumen.

Dalam teknik bentuk para penari harus mempunyai bakat, keterampilan, dan kepekaan untuk merasakan masalah-masalah bentuk tari, seperti gerak, ruang, dan waktu. Teknik medium adalah gerak. Teknik instrument, yaitu seorang penari diwajibkan untuk mengenal tubuhnya sendiri, sebagai alat ekspresi. Lewat tubuh mereka menghasilkan medium gerak. Lewat instrumen ini para penari harus menguasai teknik pernafasan secara baik, kelenturan tubuh, kontrol muskular, dan stamina.

Terdapat lima pustaka yang terkait dengan koreografi, yang di dalamnya terdiri dari elemen gerak, unsur, gerak yang menimbulkan rasa, dan tari Merak Jawa Barat. Teori yang membahas tentang elemen gerak, diantaranya buku dari Y. Sumandiyo Hadi, Koreografi: Bentuk-Teknik-Isi. Unsur-unsur gerak, yaitu La Meri, Dance Composition: The Basic Element. Gerak yang menimbulkan rasa, diantaranya buku dari Alma Hawkins, Bergerak Menurut Kata Hati dan Suzanne K Langer, Feeling and From. Tentang tari Merak sendiri, yang ditulis dalam bukunya Irawati Durban, Tari Sunda Tahun 1880-1990 Rd. Melacak Jejak Tb. Oemay Martakusumah dan Tjetje Somantri.

\section{Persepsi}

Tindakan menyusun, mengenali, dan menafsirkan informasi sensoris guna memberikan gambaran dan pemahaman tentang lingkungan. Persepsi bukanlah penerimaan isyarat secara pasif, tetapi dibentuk oleh pembelajaran, ingatan, harapan, dan perhatian. Persepsi bersifat tetap yang dipengaruhi oleh pengalaman, meliputi bentuk, ukuran, dan warna. Persepsi visual didapatkan dari indera penglihatan. Ini adalah persepsi yang paling awal berkembang dan merupakan topik utama dari bahasan secara umum, sekaligus persepsi yang biasanya paling sering dibicarakan dalam konteks sehari-hari.

\section{Sensasi}

Sensasi berupa kesan sesaat, saat stimulus baru diterima otak dan belum diorganisasikan atau diingat-ingat dengan stimulus lainnya. Energi fisik yang dihasilkan oleh objek-objek fisik yang terjadi ketika energi dalam lingkungan eksternal atau dalam tubuh merangsang respon dalam organ-organ indra. Sensasi meliputi penglihatan, bunyi, bau, rasa, dan sentuhan. 


\section{PENUTUP}

Koreografi merupakan proses penyeleksian dan pembentukan gerak ke dalam sebuah tarian, serta perencanaan gerak untuk memenuhi tujuan tertentu. Pengalaman-pengalaman seorang penari dalam kesadaran gerak, ruang, dan waktu untuk tujuan pengembangan kreativitas. Pengalaman yang dapat diarahkan atau dilakukan sendiri, serta dapat memberi sumbangan bagi pengembangan kreatif diantaranya pencarian gerak.

Seorang penari mencoba hal yang baru dalam berbagai macam gerak dengan mempadu padankan gerak melalui tubuh. Murid-murid dapat bergerak bebas mengikuti kata hatinya, berimajinasi, dan menginterpretasi terhadap apa yang telah di lihat, di dengar, atau di raba. Pencarian dasar gerak tari tradisional memberikan pengetahuan tentang keanekaragaman gerak dan kearifan lokal tentang kehidupan masyarakat penggunanya.

Sering kali dikatakan bahwa murid pemula tidak siap untuk mencipta dan mendapatkan ketubuhan baru. Melalui kesempatan yang diulang-ulang bagi aktivitas kreatif yang diarahkan sendiri, seorang penari dapat mengembangkan potensi kreatifnya. Pengalaman kreatif yang pertama dalam tari, dialami dengan beberapa tingkat kecemasan. Seorang penari yang cenderung belum berpengalaman, merasa bersalah, takut karena berbeda, dan tidak benar di dalam menggerakannya. Keinginan besar untuk menyesuaikan diri, seringkali merupakan penghalang yang dihadapi seseorang. Perasaan bersalah ini dapat kita pahami dan pengalaman seperti itu sebaiknya diarahkan agar para murid-murid dapat mengatasi rasa takutnya.

Tari sebagai karya seni dapat di gambarkan sebagai ekspresi perasaan dalam diri manusia, yang dirubah oleh imajinasi dan diberi bentuk melalui media gerak. Suatu tarian apabila disajikan sebagai objek seni menjadi sebuah pengalaman bagi para pengamat untuk di hayati dan dimengerti, melalui struktur sensasi, persepsi, dan perasaan dalam menggerakkannya.

Kreativitas dapat dikembangkan melalui eksplorasi (pencarian gerak) terhadap materi-materi gerak dan melalui organisasi gerak, menuju pada pembentukan tari. Esensi dari masing-masing pengalaman, eksplorasi atau pembentukan, suatu kesempatan yang dapat diarahkan sendiri.

\section{DAFTAR PUSTAKA}

Caturwati, Endang. 2000. R Tjetje Soemantri (18921963) Tokoh Pembaharu Tari Sunda. Tarawang, Giwangan Yogyakarta.

Durban, Irawati. 2007. Tari Sunda Tahun 1880-1990 Rd. Melacak Jejak Tb. Oemay Martakusumah dan Tjetje Soemantri, Pusbitari Press, Bandung.

Ellfeldt, Lois. 1997. Pedoman Dasar menata Tari (terjamahan Sal Murgiyanto), Jakarta: Lembaga Pendidikan Kesenian.
Goulimaris, Dimitris, dkk. 2008. The Organisation of a Distance Postgraduate Dance Programme and The Participation of Students Specialising in Dance. Journal Of Distance Education.

Hadi, Y. Sumandiyo. 1996. Aspek-Aspek Dasar Koreografi Kelompok. Yogyakarta: Manthili. 2007. Kajian Teks dan Konteks, Yogyakarta: Pustaka.

2012. Koreografi BentukTeknik-Isi, Yogyakarta: Cipta Media.

Haryanto, Budhi. 2008. Proses Pembentukan Sikap Secara Berjenjang: Studi Empiris Di Bidang Perluasan Merek. Jurnal Ekonomi dan Bisnis Indonesia. Vol. 23, No.2 (196-214).

Hawkins, Alma M. 1988. Mencipta Lewat Tari (terjemahan Y Sumandiyo Hadi), Yogyakarta: Institut Seni Indonesia Yogyakarta.

2003. Moving From Withen: A New Metod for Dance Making, (terjemahan I Wayan Dibia, Bergerak Menurut Kata Hati: Metode Baru dalam Menciptakan tari, Jakarta: MPSI. Hegel. 2003. Metafisika, Jakarta: PT. Gramedia Indah.

Sulastuti, Katarina. 2016. Konsepsi dan Indikasi Rasa dalam Tari Jawa Gaya Surakarta. Thesis Program Pascasarjana STSI Surakarta.

J. Grover, Herbert. Dance: Creative/Rhytmic Movement Education Star Superintendent, Wisconsin Department Of Republic Instruction. Langer, Suzanne K. 1953. Feeling and From, NY: Charles Scribner's Son.

Mahanal, Susriyati, dkk. 2017. Model Pembelajaran Ricosre yang Berpotensi Memberdayakan Keterampilan Berfikir Kreatif. Jurnal Pendidikan: Teori Penelitian, dan Pengem bangan. Vol. 2, No.5 (766-685).

Miller, RayDance. 2015. Dramaturgy: Definitions, Perspectives, Projections. The Oxford Handbook of Dance and Theater.

Morales, Eric César. 2018. Dance and Movement. The Oxford Handbook of Dance and Theater.

Murdiyati, Y. 2003. Tari Bedhaya Purnama Jati Karta K. R. T Sasmintadipura: Teknik dan Proses Penciptaan, dalam tesis Kajian Penciptaan Karya Seni, Pascsarjana ISI Yogyakarta.

Nazir, Moh. 1987. Metode Penelitian. Jakarta: Ghalia Indonesia.

Sedyawati, Edi, dkk. 1986. Pengetahuan Eelemen Tari dan Beberapa Masalah Tari. Jakarta: Departemen Pendidikan dan Kebudayaan.

Sun, Guoyu dkk. 2017. A Virtual Reality Dance Selflearning Framework using Laban Movement Analysis, Journal Of Engineering Science and Technology Review.

Puspitaning, Asri. 2014. Tari Merak Bodas Karya Irawati Durban Ardjo di Sanggar Pusbitari. 